кУЛЬтУРОЛОтИЯ

\author{
ИНТЕГРАЦИЯ БЕЗ АССИМИЛЯЦИИ, КАК ЦЕЛЬ ПОЛИТИКИ МУЛЬТИКУЛЬТУРАЛИЗМА В \\ АЗЕРБАЙДЖАНЕ(ФИЛОСОФСКИЙ АСПЕКТ) \\ DOI: $10.31618 /$ ESU.2413-9335.2020.7.70.568 \\ Касумова Сакина Фарзали кызы \\ ведущчий научный сотрудник \\ Института архитектуры и искусства НАНА Азербайджана , \\ доктор философии по филологии,доиент.
}

\title{
INTEGRATION WITHOUT ASSIMILATION AS THE GOAL OF STRATEGY OF MULTICULTURALISM (PHILOSOPHICAL ASPECT)
}

\author{
Kasumova Sakina Farzali kizi \\ PhD in philology, \\ Associate Professor.National academy of Sciences of Azerbaijan, \\ Institute of Architecture and Art.
}

\begin{abstract}
АННОТАЦИЯ
В статье рассматривается способность азербайджанской ментальности синтезировать достижения различных цивилизаций и способность к интегрированию их с традиционным наследием. . В данной работе сделана попытка обрисовать проблемную тематическую картину и увидеть факторы, в свете позитивной критики, которые необходимо иметь в виду для того, чтобы обозначить строгий вектор движения к прогрессивному будущему азербайджанской культуры как по праву значимой и узнаваемой на экране мировой.
\end{abstract}

\section{ABSTRACT}

The tasks of the article is to reveal the place and the dynamic of development of the concept of multiculturalism The article says about the ability of Azerbaijan culture to synthesize the achievements of different civilizations and its integration with the traditional heritage In this paper there is an attempt to review and criticize it in order to highlight the problematic side. These factors are crucial to be considered for further improvement and progress of Azerbaijani culture as a respected and honored in front of the world's.

Ключевые слова:искусство,ментальность, цивилизация,традиции,культура

Keywords: Art, mentality, civilization, traditions, the culture

Интеграция без ассимиляции, концепция, которая позволяет сохранить многообразие культурных идентичностей в мультукультурном обществе. Данная концепция логически имманентна идеи мультикультурного общества, поскольку сосуществование различных культур в той или иной стране подразумевает сохранение их культурного ядра. Таким образом, из данного положения следует, что политика толерантности служат необходимым звеном связующим многообразие культурных идентичностей внутри мультикультурного общества. В отношении претворения данной модели в жизнь, Азербайджан служит убедительным образцом, поскольку интеграция различных культур без ассимиляции культурного ядра, свершившийся факт. Условия, позволившие Азербайджану стать наглядным примером успешного претворения мультикультурной модели общества в жизнь, исторические, географические, и, пожалуй, в большей степени, социокультурные.

Располагаясь на пересечении Европы и Азии Азербайджан, испытывая на себе влияни западной и восточной цивилизаций, синтезировал в себе диалектический подход к обеим, став зоной культурного взаимоперевода, что со временем позволило азербайджанской ментальности стать гибче и перцептивней в отношении понимания и интеграции многообразия культур. Что характеризует особенность Азербайджана, помимо всего прочего, так это способность синтезировать в себе многообразие культур, сохраняя свою идентичность. Данный тезис опосредованно намекает на то, что доминантная культура, в той или иной стране, практикующей мультикультурную политику, необходима в качестве культурного ядра, задача которого заключается в том, чтобы не позволить сосуществованию многообразных культур деградировать в анархический пост-культурный релятивизм. Интеграция без ассимиляции, таким образом, апеллирует к наличию доминантной культуры, задача которой в отношении других культур заключается, не в репрессивных формах подавления инаковости, но напротив, в том, чтобы служить надежным гарантом их сосуществования в той или иной стране. Таким образом, традиционализм является необходимым фактором в отношении интеграции культур без ассимиляции. Наличие доминантных культур внутри глобального общества позволяет свести на нет опасность распыления культур в тотальной ассимиляции, в поле абстрактной идеи всеобщности, лишенной какой-либо прочной идентичности.

«Особенный культурный фон или корни, на которые всегда опирается всеобщая 
мультикультуралистская позиция, - это не ее «истина», скрывающаяся за маской всеобщности, а скорее, нечто совершенно противоположное: некие особые корни - это фантазматический экран, скрывающий то обстоятельство, что субъект уже окончательно лишился всяких корней, что его истинное положение - это пустота всеобщности.»[2]

Таким образом, чтобы избежать опасности стать жертвами идеологической фантасмагории тотальной культурологической всеобщности, лишенной всякогоцентра, необходима интеграция без ассимиляции, опирающаяся на наличие доминантной культуры. Эта прививка традиционализма способна выработать культурный иммунитет противкультурологического нигилизма, опирающегося на «фантазматическую» идею тотальной, релятивистской всеобщности, лишенной всякого центра. Критика мультикультурного проекта, как раз была направлена, по большему счету против нигилистической идеи тотальной, глобальной ассимиляции, разрушающий многообразия идентичностей, которое собственно и является, залогом мультикультурного общества. «В современную эпоху преобладающей социальной формой «конкретной всеобщности» является национальное государство как условие наших особенных социальных идентичностей: определенная форма моей общественной жизни (рабочий, профессор, политик, фермер, юрист...) - это определенная форма участия во всеобщей жизни национального государства. По отношению к этой логике превращения, гарантирующей идеологическую сплоченность национального государства, Соединенные Штаты Америки играют уникальную роль исключения: ключевая составляющая традиционной «американской идеологии» заключается в попытке превращения преданности особенным этническим корням в выражение «бытия американцем»: чтобы быть «хорошим американцем», не нужно отрекаться от этнических корней - итальянцы, немцы, чернокожие, евреи, греки, корейцы - «все они американцы», то есть сама особенность их этнической идентичности, путь, которого они «держатся», делают их американцами»[2].

Позитивное развитие мультикультурализма не должно выражаться в отказе от культурных корней, напротив, этнокультурная идентичность необходима в качестве гаранта сосуществования различных культурных идентичностей, ведь чтобы существовало культурное многообразие необходимо наличие этнокультурной идентичности внутри того или иного общества. А это, опять-таки, подразумевает наличие доминантной культуры, как гаранта стабильности мультикультурного общества. Доминантная культура призвана заботится о полиэтническом, культурном многообразии так, чтобы не дать мультикультурному обществу выродиться в нигилистический релятивизм тотальной всеобщности, в тотальную ассимиляцию без интеграции, в которой никакое наличие многообразия культур не будет возможным, в силу отсутствия идентичностей, опирающихся на традицию. Доминантная культура сплачивает культуры вокруг своего культурного ядра, организуя порядок и социальную функциональность общества. В этом отношении сосуществование многообразия культур, в рамках доминантной культуры апеллирует к идее социокультурного двойного гражданства, в рамках которого носители различных культурных идентификаций, идентифицируют себя также с доминантной культурой, служащей основой для синтеза функционального и стабильного общества.

Примером подобного стабильного мононационального общества, выступает Азербайджан, на примере которого можно увидеть воплощение идеи интеграции без ассимиляции, живой пример реализации мультикультурной модели общества, опирающуюся на разумную социокультурную политику.

Анализируя

социологические проблемы,невозможно обойти стороной важнейшие измерения, в которых они выражаются, и более того, в которых они формируются. А именно измерение культуры киберпространства интернета. В этом контексте данная тема, интеграция без ассимиляции, находит свое продолжения в рамках виртуального пространства социальной культуры.

«Web-online Интернета позволяет, оставшись наедине с экраном компьютера, путешествовать и развивать культуру кибер-пространства, территория которого, сотканная из связей, интерактивна и может порождать самые настоящие межнациональные виртуальные сообщества. Члены этого подлинно "мирового клуба" виртуальной реальности живут одновременно и в рамках реального, и в иллюзии игровых возможностей информации. С одной стороны, все это открывает совершенно новые перспективы и устанавливает новое мироотношение, основанное на безграничном универсализме, но с другой обостряет риск "присвоения" культуры, к которому располагает общество потребления. Как представляется, "присвоение" дробит дискурс постмодернизма на фрагменты, делая его частичным и незавершенным.»[I]

Тот факт, что даже в свободном от всякого принуждения пространстве интернета люди тянутся к интегрированным сообществам свидетельствует о том,что человеку на онтологическом уровне необходима некая общность, интегрированность в нее. Но общности внутри интернета не могут соперничать с общностями реальной идентификации, налагающей некие ограничения и требования к их участникам, некие правила игры, которые делают ее серьезной, и придают человеческому бытию онтологическую укорененность . В силу этого национальная идентичность и требования культуры относительно соблюдение квазитрадиционных норм по сей день актуальны, так как придают 
человеческому бытию экзистенциальную аутентичность в рамках социума. Это еще раз говорит о том, что мультикультурная модель общества должна включать в себя различные культурно-этнические идентификации, общности, дабы включить их в поликультурную систему, не ассимилируя идентичности в абстрактную всеобщность, в которой всякая идентичность, призванная служить многообразию сосуществующих культур, распыляется в нигилистичном посткультурном релятивизме

\section{Список литературы}

1.Фернандо Аинса .Реконструкция утопии/ "Наследие", Editions UNESCO /Москва, 1999

2.СлавойЖижек.Интерпассивность.Желание; влечение,мультикультурализм/Алетейя.

Издательская серия. Лакановские тетради. Санкт Петербург.2005. 